\title{
$\beta$-elemene acts as an antitumor factor and downregulates the expression of survivin, Bcl-xL and Mta-1
}

\author{
XIAN CHEN $^{1,2^{*}}$, YI WANG ${ }^{2 *}$, HONGMEI LUO $^{3}$, ZHIGANG LUO $^{2}$, TAO ZHANG $^{2}$, NING YANG ${ }^{2}$, \\ XIANGYANG LONG ${ }^{2}$, HUANG XIE ${ }^{2}$, WEIBING QIU ${ }^{2}$, BIAO ZHANG $^{2}$, JUN DING $^{2}$ and LUOYAN YANG ${ }^{1}$ \\ ${ }^{1}$ Department of Urology, the Second Xiangya Hospital of Central South University, Changsha, Hunan 410011; \\ ${ }^{2}$ Department of Urology, Second Affiliated Hospital of University of South China, Hengyang, Hunan 421001; \\ ${ }^{3}$ Department of Histology and Embryology, University of South China, Hengyang, Hunan 421001, P.R. China
}

Received March 5, 2012; Accepted July 19, 2012

DOI: $10.3892 / \mathrm{mmr} .2012 .1018$

\begin{abstract}
. $\beta$-elemene, a non-cellular antineoplastic agent, may be used to effectively inhibit the growth and proliferation of various types of tumor cells by inhibiting the nucleic acid synthesis or inducing their apoptosis and differentiation. The aim of this study was to investigate the expression, as well as the effects, of Mta-1, survivin and Bcl-xL in T24 bladder cancer cells following $\beta$-elemene treatment. The expression of the three proteins in T24 cells following $\beta$-elemene treatment was analyzed by immunocytochemistry staining and western blot analysis. The survival rate and apoptosis of T24 cells following $\beta$-elemene treatment was detected by MTT assay and TUNEL staining. We analyzed the internal corelations between apoptosis-associated genes, tumor metastasis-associated genes (cancer genes) and cell apoptosis, and investigated the mechanism of action by which $\beta$-elemene induces the apoptosis of T24 cells at a molecular level. These results provide scientific evidence for further study on the anticancer effect of $\beta$-elemene in carcinoma of the urinary bladder. In this study, it is shown that $\beta$-elemene downregulates the expression of survivin, Bcl-xL and Mta-1 in tumor cells. The apoptosis of T2 4 cells is dependent on the dosage and length of incubation time of $\beta$-elemene.
\end{abstract}

\section{Introduction}

$\beta$-elemene is a grease monomer extracted from volatile oils of Wenchow turmeric rhizome, a Chinese medicine that is capable of promoting blood circulation and removing blood stasis. $\beta$-elemene belongs to the sesquiterpene derivatives, which

Correspondence to: Professor Luoyan Yang, Department of Urology, the Second Xiangya Hospital of Central South University, Changsha, Hunan 410011, P.R. China

E-mail: luoyany@yahoo.com

*Contributed equally

Key words: $\beta$-elemene, survivin, Bcl-xL, Mta-1, human bladder cancer do not contain hydrogen. In comparison with the majority of chemotherapeutics, this medicine has fewer side-effects, with no damage to the liver and kidneys detected. With no myelosuppression, the preparations have been proven to have curative effects on a wide variety of tumor types according to experimental and clinical pharmacology (1). Research has shown that $\beta$-elemene has marked inhibitory effects on certain tumor types, possibly by inducing apoptosis and inhibiting cell proliferation $(2,3)$.

The Bcl-2 gene family includes important apoptosis-regulating genes. B-cell lymphoma $\mathrm{x}(\mathrm{Bcl}-\mathrm{x})$ is an important member of the Bcl-2 gene family. Bcl-x has two mRNA isomerides, $\mathrm{Bcl}-\mathrm{xL}$ and $\mathrm{Bcl}-\mathrm{xs}$, which are of different sizes and have opposing functions. Bcl-xL is capable of forming ducts in the cell membrane for ions and protein to get into and out of mitochondria in order to promote apoptosis $(4,5)$. Bcl-x may destroy the cell calcium balance, and inhibit apoptosis by reducing the activity of thrombocytes (6). In cisplatin-resistant ovarian cancer, $\beta$-elemene can induce and increase the activity of caspase-9, downregulate the expression of Bcl-2 and Bcl-xL, and increase the release of cytochrome $\mathrm{c}$ into the cytoplasm from the mitochondria. These data indicate that $\beta$-elemene sensitizes chemoresistant ovarian carcinoma cells to apoptosis induced by cisplatin (7).

Survivin belongs to the family of inhibitors of apoptosis protein (IAP). Combined with active capase- 3 and caspase-7, it may inhibit apoptosis induced by various stimuli. Survivin is involved in the process of regulating and controlling tumor apoptosis and may be a new target for oncotherapy (8). Research shows that in the cell strains of ovarian cancer, $\beta$-elemene induces and increases the activity of caspase- 8 , caspase-9, caspase- 3 , caspase- 7 and caspase-10, which indicates that the effect of elemene on cell death may be mediated through the death receptor signaling and/or mitochondrial release of cytochrome c-dependent pathways. These data suggest that elemene may have an effect on cisplatin sensitivity in human ovarian carcinoma cells through the regulation of cell cycle control and the apoptotic signaling pathway (9). In our research, it was shown that $\beta$-elemene is capable of downregulating the expression of survivin and this may be related to the fact that $\beta$-elemene induces and increases the activity of caspase- 3 and caspase- 7 . 
Metastasis-associated gene 1 (Mta-1) is a newly-discovered gene associated with the metastasis of tumors (10), whose gene products are capable of playing a role in the regulation of the signaling pathways and expression of genes. It is an important protein molecule that positively controls the process of tumor metastasis. Research in oral squamous carcinoma has shown that MTA1 overexpression in oral squamous cell carcinoma (SCC) may be associated with increased invasive ability, which may cause lymph node metastasis (11). In this study, we found that $\beta$-elemene is capable of downregulating the expression of survivin, Bcl-xL and Mta-1 in tumor cells, and inducing the apoptosis of tumor cells. The apoptosis of T24 cells is dependent on the dosage and incubation time of $\beta$-elemene.

\section{Materials and methods}

Cell culture. The bladder cancer cell line T24 was purchased from the cell centre of XiangYa Medical College, Central South University. The cells were cultured in RPMI-1640 medium (Gibco, Invitrogen, Carlsbad, CA, USA) complemented with $10 \%$ fetal bovine serum (Gibco). All cell lines were cultured in a humidified incubator $\left(5 \% \mathrm{CO}_{2}\right)$ at $37^{\circ} \mathrm{C}$. All experiments were conducted according to the ethical guidelines of University of South China.

MTT colorimetric assay. $\beta$-elemene (Dalian Jingang Pharmaceuticals Ltd., China) at different concentrations (0.004, 0.008, 0.01, 0.02, 0.04, 0.06 and $0.08 \mathrm{mg} / \mathrm{ml}$, respectively) was added to wells of T24 cells in a 96-well plate, and each group of cells was paralleled for four wells. Untreated T2 4 cells and blank controls were also included in the plate. The cells were cultured for $24 \mathrm{~h}$, and after MTT was added to each group, the cells were cultured for another $48 \mathrm{~h}$. The light absorption value (optical density) was then measured at the wavelength of $492 \mathrm{~nm}$. The optical density of each group of cells was calculated by setting the blank control parameter as 0 and taking the average.

In-situ hybridization. T24 bladder cancer cells were cultured to the exponential phase. Following digestion, fresh RPMI-1640 was added to the cells, and the cells were resuspended into 6-well plates with cover glasses in each well pre-treated by Poly-L-Lysine solution at the concentration of $5 \times 10^{5}$ cells per well. The control group of T24 cells was cultivated with medium for 6,12 and $18 \mathrm{~h}$. To test the dose-effect, $\beta$-elemene was added to the cells with three different concentrations of $0.008,0.014$ and $0.02 \mathrm{mg} / \mathrm{ml}$, respectively, and the cells were cultivated for $12 \mathrm{~h}$. To test the effect of aging, $\beta$-elemene was added, with a final concentration of $0.014 \mathrm{mg} / \mathrm{ml}$ into T2 4 cells that were cultured for $24 \mathrm{~h}$ in a 6 -well plate, and the cells were then cultivated for 6,12 and $18 \mathrm{~h}$, respectively. Cover glasses with attached T24 cells were removed, rinsed with $0.02 \mathrm{M}$ PBS and stored at $-20^{\circ} \mathrm{C}$ after fixation with pure acetone at room temperature for $15 \mathrm{~min}$. The cover glasses were then used for further analysis. Apoptosis was determined by TUNEL assay, and performed using a kit purchased from Wuhan Boshide Company, China. Cells with a darkly tinted nucleus were apoptotic cells. Cell apoptosis rate = number of apoptotic cells/total number of cells x $100 \%$.
Mta-1 mRNA was detected by in situ hybridization using the DIG Random Labeling and Detection kit I (POD) (Boshide Co.) according to the manufacturer's instructions. The Mta-1 mRNA in situ hybridization probe (5' end mark digoxin) was synthesized by Shanghai Sangon Bioengineering Technical Service Ltd., and the sequence was 5'-gtttccgaggatgagagcagcttgcggat-3'.

Immunocytochemistry analysis. A semi-quantitative method was used to divide the color intensity into three levels, one point for no color, two points for low intensity color and three points for yellow. The percentage of positive cells was also divided into three levels, one point for level $1(\leq 25 \%)$, two points for level $2(26-75 \%)$, and three points for level $3(\geq 76 \%)$. The final score of each coverslip of cells was calculated by multiplying the scores of the two grading methods (1-9 points). If the score was $\geq 3$ points, the slip was determined as positive, and if the score was $<3$ points, the slip was determined as negative. In total, 100 cells in each field of vision were counted, and 20 coverslips of cells in each group were observed $(n=20)$. The expression ratio of positive cells (\%) was calculated by dividing the numbers of positive cells by the number of total cells. The results were displayed as a percentage \pm standard deviation (SD). Monoclonal mouse anti-Human Bcl-xL (ZM-0301) was purchased from Beijing Zhongshan Biotechnology Co.

Western blot analysis. Total cellular proteins were isolated and separated on SDS-PAGE gels. Western blotting was used to test the MTA-1 protein expression of T2 4 cells. The primary antibody (1:400) against Mta-1 and the primary antibody against $\beta$-actin (1:1000) were purchased from the Fox Chase Cancer Center (Philadelphia, PA, USA). The membrane was incubated with horseradish peroxidase-conjugated secondary antibodies (Cat. No. sc-2030; Santa Cruz Biotechnology, Santa Cruz, CA, USA), visualized by an enhanced chemiluminescence detection kit (Thermo Scientific, Pierce, Rockford, IL, USA) and exposed to film. $\beta$-actin was used as a loading control.

Statistical analysis. Data were analyzed using SPSS 11.5 and SPSS 13.0 software. A comparison among groups was performed by the non-parametric test of rank transformation (Kruskal-Wallis test method), while the correlation test was performed by non-parametric correlation analysis (Spearman coefficient of rank correlation). $\mathrm{P}<0.05$ was considered to indicate a statistically significant difference. One-way analysis of variance (ANOVA) was also used for analysis.

\section{Results}

The survival rate of $T 24$ cells is negatively correlated with the incubation time of $\beta$-elemene. To analyze the effect of $\beta$-elemene on T24 bladder cancer cells, $\beta$-elemene at increasing concentrations was incubated for 24 or $48 \mathrm{~h}$ with T24 cells. The survival rate of the cells was calculated by the OD value of the MTT assay. As shown in Fig. 1, the survival rate of T24 cells treated with $\beta$-elemene for $48 \mathrm{~h}$ was lower than those treated for $24 \mathrm{~h}$, indicating that the prolonged incubation time more effectively decreases the survival of T24 cells. The survival rate of T24 cells in groups incubated with $\beta$-elemene for 24 and $48 \mathrm{~h}$ at a concentration of less than 


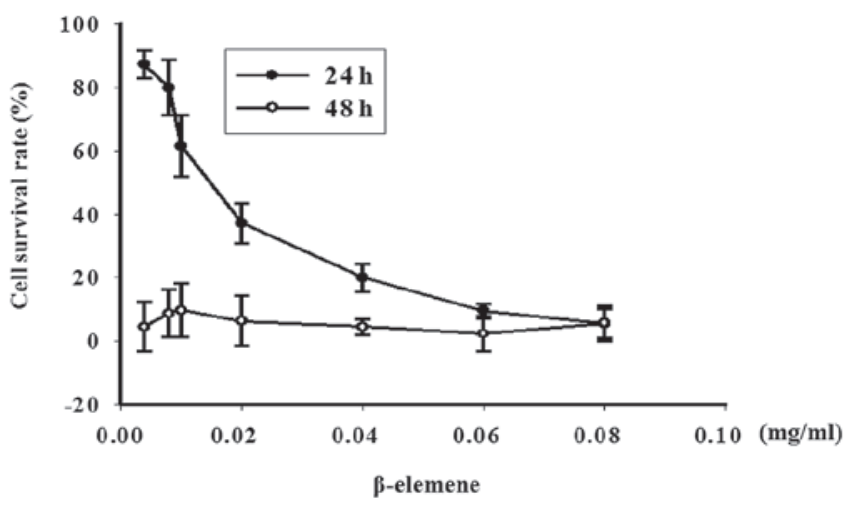

Figure 1. The survival rate of T24 cells was measured by the MTT colorimetric assay. T24 cells were treated with various doses of $\beta$-elemene for 24 or $48 \mathrm{~h}$. The survival rates of T24 cells were determined by measuring the corresponding OD values.

$0.02 \mathrm{mg} / \mathrm{ml}$ was more than 60 and $45 \%$, respectively, while the survival rate of T2 4 cells in groups with a $\beta$-elemene dose of more than $0.02 \mathrm{mg} / \mathrm{ml}$ was decreased to less than 40 and $30 \%$, respectively. When $0.06 \mathrm{mg} / \mathrm{ml} \beta$-elemene was added and incubated for 24 and $48 \mathrm{~h}$, the average survival rate of T24 cells only reached approximately $10 \%$ (Fig. 1).

The apoptosis of T24 cells is dependent on the dosage and incubation time of $\beta$-elemene. To determine the effect of $\beta$-elemene on the apoptosis of T2 4 cells, TUNEL analysis was performed for T 24 cells treated with $0.014 \mathrm{mg} / \mathrm{ml} \beta$-elemene for different times $(6,12$ or $18 \mathrm{~h}$ ) (Fig. $2 \mathrm{~A})$, or treated with various concentrations of $\beta$-elemene $(0.008,0.014$ and $0.02 \mathrm{mg} / \mathrm{ml})$ for $12 \mathrm{~h}$ (Fig. 2B). Cells that appeared yellow or brown from the result of TUNEL were considered to be apoptotic cells. By counting the number of apoptotic cells, it was found that the apoptotic rate of T24 cells increased upon the elevation of $\beta$-elemene concentration. Moreover, the apoptotic rate of T24 cells also increased upon longer incubation times of $\beta$-elemene. These results suggest that the apoptosis of T24 cells is dependent on the dosage and incubation time of $\beta$-elemene.

$\beta$-elemene affects expression of survivin and Bcl-xL in T24 cells. To determine whether $\beta$-elemene affects protein expression, T24 cells were treated with $\beta$-elemene at various doses for different times. The expression of survivin was detected. As shown in Fig. 3A and B, compared with that in the control group, the average number of positive cells expressing survivin in the T24 cell intervention groups that were either treated with different doses of $\beta$-elemene $(0.008,0.014$ and $0.02 \mathrm{mg} / \mathrm{ml})$, or incubated with $\beta$-elemene for different times $(6,12$ and $18 \mathrm{~h})$, were markedly decreased, while the cell apoptosis rate in $\beta$-elemene-treated cell groups was markedly higher than that in the non-intervention group. Prior to intervention, survivin showed marked positive expression in T2 4 cells. When T24 cells were treated with $0.014 \mathrm{mg} / \mathrm{ml}$ $\beta$-elemene for $6 \mathrm{~h}$, the decreased expression of survivin was not clear. However, after another $6 \mathrm{~h}$, the expression levels of the two proteins began to decrease, and after $18 \mathrm{~h}$, the decrease was statistically significant $(\mathrm{p}<0.01)$. Thus, the expression of the two proteins was dependent on the dosage and incubation
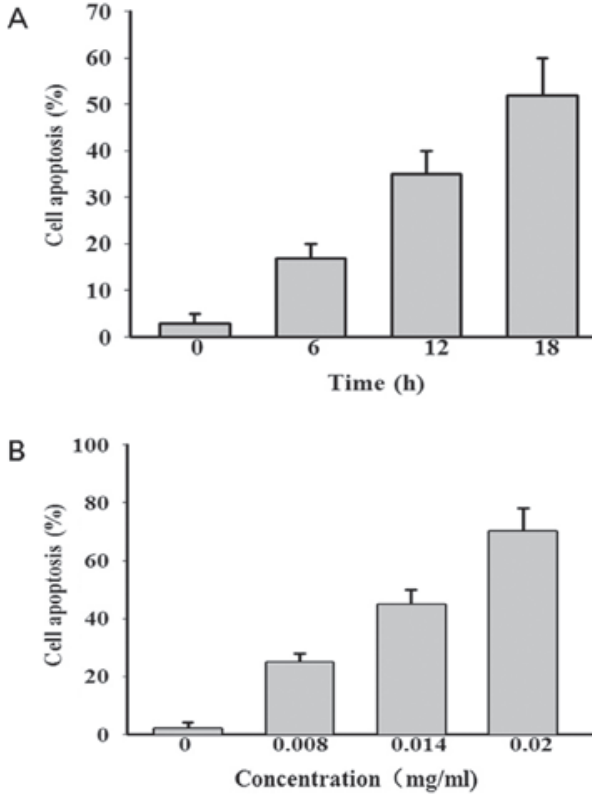

Figure 2. Apoptosis rate of T24 cells detected by TUNEL staining. (A) The cell apoptosis rate was counted in T24 cells treated with $0.014 \mathrm{mg} / \mathrm{ml}$ $\beta$-elemene from 0 to $18 \mathrm{~h}$. Cells with darkly tinted nuclei were apoptotic cells. (B) The cell apoptosis rate was counted in T24 cells treated with $\beta$-elemene at various concentrations for $12 \mathrm{~h}$.

time of $\beta$-elemene; in other words, with the increase of drug concentration and the extension of the incubation time, the protein levels of survivin significantly reduced. Nonparametric correlation analysis revealed a negative correlation between the decrease of the protein expression levels of survivin and the treatment concentration and incubation time of $\beta$-elemene. Furthermore, the cell apoptosis rate was also negatively correlated with the treatment concentration and incubation time of $\beta$-elemene. Bcl-xL expression was also detected using the same method as for detection of survivin, and similar results to those of survivin expression were achieved (data not shown).

Expression of Mta-1 mRNA following $\beta$-elemene treatment. The expression of Mta-1 mRNA was detected in T24 cells during $\beta$-elemene treatment by in situ hybridization. As shown in Fig. 3C and D, when Mta-1 mRNA was positively expressed, the T24 cell cytoplasm was tinted and the cell nucleus was slightly tinted yellow or brown. In human bladder cancer T24 cells, the expression of Mta-1 mRNA was mainly detected inside the cell nucleus, with only slight yellow or brown staining in the cell cytoplasm. Mta-1 mRNA in T24 cells is mainly expressed in the cell cytoplasm.

Expression of Mta-1 protein following $\beta$-elemene treatment. To analyze changes in the expression of Mta-1 protein following treatment, T24 cells were incubated with $0.002 \mathrm{mg} / \mathrm{ml}$ $\beta$-elemene and the expression of Mta-1 was determined by western blot analysis. As is shown in Fig. 4 , $\beta$-elemene downregulated the expression of Mta-1 protein in T24 cells from $24 \mathrm{~h}$ after treatment, and the downregulation of expression was time-dependent; that is, the expression of Mta- 1 protein was reduced after 48 and $72 \mathrm{~h}$ of $\beta$-elemene treatment. $\beta$-actin was used as a loading control. This result further indicated 
A
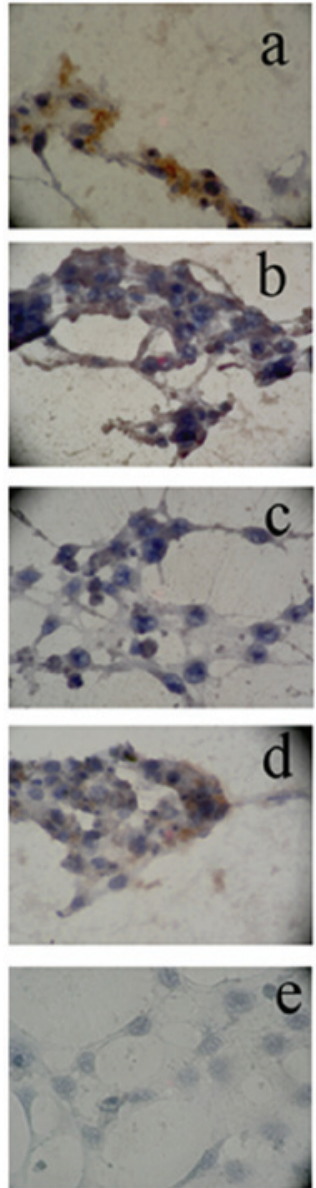

B
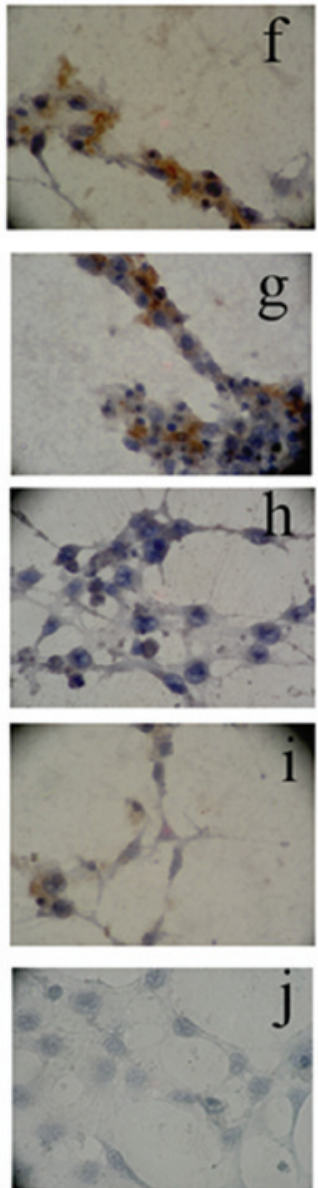

$\mathrm{C}$
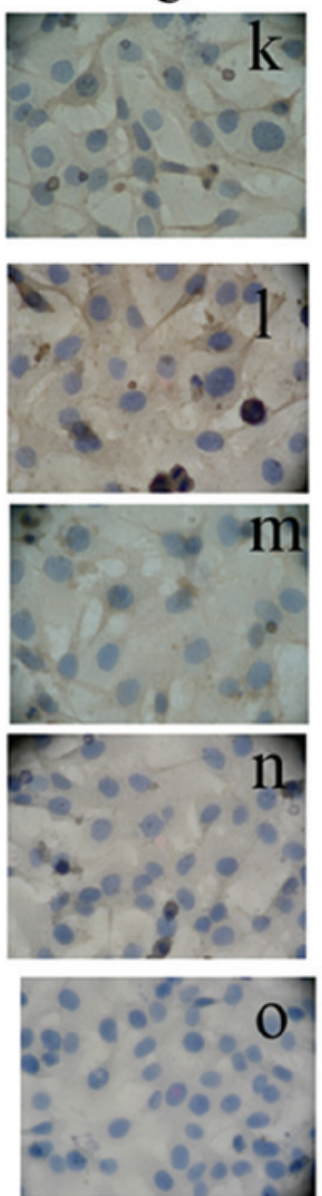

$\mathrm{D}$
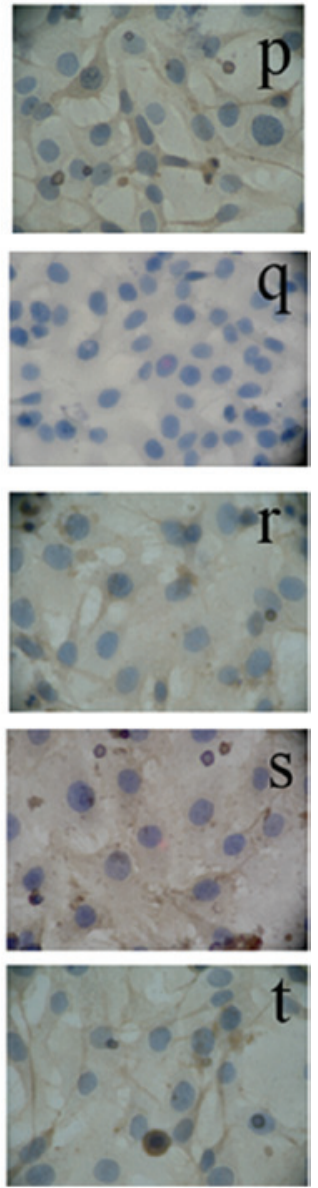

Figure 3. Detection of survivin and Mta-1 mRNA in human bladder cancer T24 cells. (A) Expression of survivin protein detected using an immunohistochemical method (SP method, $\mathrm{x} 400$ ). T2 4 cells were treated with $\beta$-elemene at a dose of $0.014 \mathrm{mg} / \mathrm{ml}$ for various incubation times. The positive expression of survivin was detected by immunohistochemistry. (a) untreated T24 cells; (b-d) T24 cells treated with $\beta$-elemene for 6,12 and $18 \mathrm{~h}$; (e) immunocytochemically negative control T24 cells. (B) T24 cells were treated with $\beta$-elemene at various concentrations for $12 \mathrm{~h}$. The expression of survivin was detected by the SP method (x400). (f) Untreated T24 cells; (g-i) T24 cells treated with $\beta$-elemene at concentrations of $0.008,0.014$ and $0.02 \mathrm{mg} / \mathrm{ml}$; (j) immunocytochemically negative control T24 cells. (C) Expression of Mta-1 mRNA detected by in situ hybridization (x400). T24 cells were treated with $\beta$-elemene at a dose of $0.014 \mathrm{mg} / \mathrm{ml}$ for various incubation times. The expression of Mta-1 mRNA was detected by immunohistochemistry. (k) Untreated T24 cells; (1-n) T24 cells treated with $\beta$-elemene for 6,12 and $18 \mathrm{~h}$; (o) immunocytochemical negative control T24 cells. (D) Expression of Mta-1 mRNA detected by in situ hybridization (x400). T24 cells were treated with $\beta$-elemene at various concentrations for $12 \mathrm{~h}$. The expression of Mta-1 mRNA was detected by immunohistochemistry. (p) Untreated T24 cells; (q-s) T24 cells treated with $\beta$-elemene at concentrations of $0.008,0.014$ and $0.02 \mathrm{mg} / \mathrm{ml}$; (t) immunocytochemically negative control T24 cells.

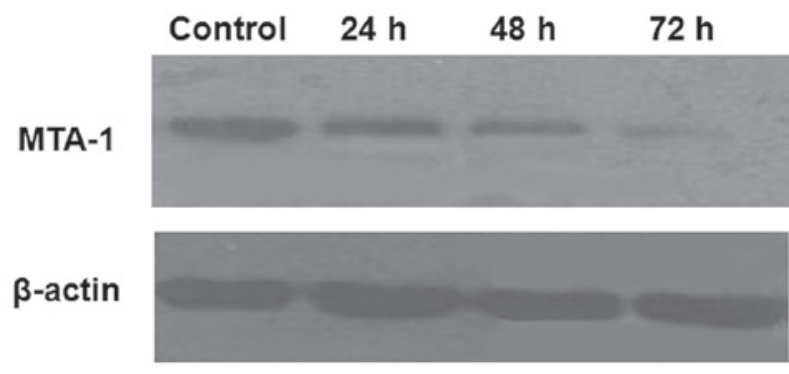

Figure 4. Western blot analysis of Mta-1 protein expression in T24 cells treated with $0.002 \mathrm{mg} / \mathrm{ml} \beta$-elemene. $\beta$-actin was used as a loading control.

that $\beta$-elemene treatment can inhibit the expression of Mta-1 mRNA protein in T24 cells.

Correlation analysis between expression of survivin and Bcl-xL as well as between Mta-1 protein or Mta-1 mRNA and the expression of survivin and Bcl-xL in T24 cells incubated with different doses of $\beta$-elemene for the same duration of time. By nonparametric correlation analysis it was found that when T24 cells were treated with various doses of $\beta$-elemene for the same incubation time of $12 \mathrm{~h}$, the expression of survivin and $\mathrm{Bcl}-\mathrm{xL}$ protein was positively corelated, with a correlation coefficient (RS) of $0.915(\mathrm{P}<0.01)$. The expression of Mta-1 protein had a positive correlation with that of both survivin and Bcl-xL, with an RS of 0.954 and 0.943 , respectively $(\mathrm{P}<0.01)$. Similarly, the expression of Mta- 1 mRNA also had a positive correlation with that of survivin and Bcl-xL, with an RS of 0.933 and 0.974 , respectively $(\mathrm{P}<0.01)$. Moreover, there was a positive correlation between the expression of Mta-1 protein and Mta-1 mRNA (RS, 0.952; $\mathrm{P}=0.000$ ) (Table I).

Correlation analysis between expression of survivin and Bcl-xL as well as between Mta-1 protein or Mta-1 mRNA and the expression of survivin and Bcl-xL in T24 cells incubated 
Table I. The correlation between the expression of Bcl-xL, survivin proteins and Mta-1 mRNA in T24 cells treated with different doses of $\beta$-elemene for $12 \mathrm{~h}$.

\begin{tabular}{lcccc}
\hline & Mta-1 & Mta-1 mRNA & Survivin & Bcl-xL \\
\hline Mta-1 RS & 1.000 & 0.952 & 0.954 & 0.943 \\
P-value & - & 0.000 & 0.000 & 0.000 \\
Mta-1 mRNA RS & 0.952 & 1.000 & 0.933 & 0.974 \\
P-value & 0.000 & - & 0.000 & 0.000 \\
Survivin RS & 0.954 & 0.933 & 1.000 & 0.915 \\
P-value & 0.000 & 0.000 & - & 0.000 \\
Bcl-xL RS & 0.943 & 0.974 & 0.915 & 1.000 \\
P-value & 0.000 & 0.000 & 0.000 & - \\
\hline
\end{tabular}

T24 cells were treated with different doses of $\beta$-elemene $(0.008$, 0.014 and $0.02 \mathrm{mg} / \mathrm{ml}$ ) for $12 \mathrm{~h} . \mathrm{P}<0.05$ was considered as statistically different. RS, correlation coefficient.

Table II. The correlation between Mta-1 protein and Mta-1 mRNA and the expression of survivin and $\mathrm{Bcl}-\mathrm{xL}$ proteins in T24 cells incubated with $\beta$-elemene for different durations.

\begin{tabular}{lcccc}
\hline & Mta-1 & Mta-1 mRNA & Survivin & Bcl-xL \\
\hline Mta-1 RS & 1.000 & 0.971 & 0.951 & 0.960 \\
P-value & - & 0.000 & 0.000 & 0.000 \\
Mta-1 mRNA RS & 0.971 & 1.000 & 0.955 & 0.973 \\
P-value & 0.000 & - & 0.000 & 0.000 \\
Survivin RS & 0.951 & 0.955 & 1.000 & 0.936 \\
P-value & 0.000 & 0.000 & - & 0.000 \\
Bcl-xL RS & 0.960 & 0.973 & 0.936 & 1.000 \\
P-value & 0.000 & 0.000 & 0.000 & - \\
\hline
\end{tabular}

Nonparametric correlation analysis was performed on T24 cells treated with $0.014 \mathrm{mg} / \mathrm{ml} \beta$-elemene for different times $(6,12$ and $18 \mathrm{~h}) . \mathrm{P}<0.05$ was considered as statistically different. RS, correlation coefficient.

with the same doses of $\beta$-elemene for different durations. Nonparametric correlation analysis showed that when T24 cells were incubated with $0.014 \mathrm{mg} / \mathrm{ml} \beta$-elemene for different time durations $(6,12$ and $18 \mathrm{~h}$ ), expression of survivin and Bcl-xL protein was positively correlated (RS, $0.936 ; \mathrm{P}<0.01)$. The expression of Mta-1 protein had a positive correlation with the expression of survivin and Bcl-xL protein, with an RS of 0.951 and 0.960 , respectively $(\mathrm{P}<0.01)$. Similarly, the expression of Mta-1 mRNA also had a positive correlation with the expression of survivin and Bcl-xL protein, with an RS of 0.955 and 0.973 , respectively $(\mathrm{P}<0.01)$. Finally, there was a positive correlation between the expression of Mta-1 protein and Mta-1 mRNA, with an RS of 0.971 ( $\mathrm{P}<0.01$; Table II).

\section{Discussion}

In recent years, progress has been achieved through studies on the role of $\beta$-elemene in cancer treatment, including its role in inhibiting tumor cell proliferation, promoting tumor cell apoptosis, inducing tumor cell differentiation (tumor reversion), inhibiting the telomerase activity of tumor cells, inhibiting the expression of cancer genes such as Bcl-2 and $\mathrm{C}$-myc and inducing dissociated $\mathrm{Ca}^{2+}$ in tumor cells, as well as its antioxidant function, immunoregulation properties, drug resistance and its resistance to neoplasm metastasis. In this experiment, $\beta$-elemene was selected to induce the apoptosis of human bladder T24 cells cultured in vitro, and changes in the expression of survivin, Bcl-xL and Mta-1 proteins, as well as Mta-1 mRNA, were detected so as to investigate the antitumor mechanism induced by $\beta$-elemene.

In 1997, the survivin gene was reported for the first time (12). Survivin belongs to the family of inhibitor of apoptosis proteins (IAP). It is the strongest apoptosis inhibiting factor discovered to date. The main function of survivin is to inhibit tumor cell apoptosis and promote tumor cell proliferation. It is also associated with the susceptibility to tumor chemotherapeutics and the prognosis of cancer. The human survivin gene is $15 \mathrm{~kb}$ long and is located on 17q25, with 4 exons and 3 introns. The survivin protein contains 142 amino acids, and is the smallest of the IAP proteins.

Overexpression of survivin may inhibit cell apoptosis by inhibiting caspase expression in a direct or indirect way (via P21), and thus cause abnormal cell proliferation and extensive transformation. The mechanism by which survivin indirectly inhibits caspase is by forming a complex with cyclin-dependent kinase CDK4, resulting in the release of P21 from the CDK4 complex and then the combination of $\mathrm{P} 21$ with mitochondrion caspase- 3 to restrain its activation and prevent cell apoptosis (13). Survivin is expressed at the G2/M-phase in the cell cycle. Intervention of the interaction between survivin, microtubules and microtubule inhibitors leads to the loss of the anti-apoptotic activity of survivin, as well as the activation of caspase-3, and eventually the apoptosis of cells (14).

This study revealed that T24 cells expressed survivin, which is associated with the high proliferation property of T24 cells. This is similar to the findings in bladder cancer tissues by Chen et al (15), which indicate a possibility that the survivin gene may be regarded as a new target of genetic therapy in bladder cancer.

The mRNA of Bcl-xL encodes a protein composed of 233 amino acids with a molecular weight of 29-31 kDa, which contains the complete $\mathrm{BH} 1, \mathrm{BH} 2, \mathrm{BH} 3$ and TM zone and has $74 \%$ homology to Bcl-2. Bcl-xL forms pores in the cell membrane for ions and protein to get into and out of mitochondria, and thus promotes apoptosis (4,5). However, Bcl-xL may also destroy the calcium balance of cells and inhibit apoptosis by reducing the activity of thrombocytes (6). Moreover, Bcl-xL not only inhibits cell apoptosis and boosts survival of cells, but also resists apoptosis mediated by cancer suppressor genes such as P53 and C-myc (16). Research has shown that the Bcl-xL gene was highly expressed in many types of tumor cells $(17,18)$, and that Bcl-xL, which plays a role in the occurrence and development of bladder cancer, may be used for the prognosis and treatment of the relapse of bladder cancer $(19,20)$.

The results of this study proved that the bladder carcinoma cells had a high expression of Bcl-xL protein, and the expression rate of Bcl-xL protein in T24 cells treated with $0.008 \mathrm{mg} / \mathrm{ml}$ 
$\beta$-elemene was markedly low compared with that in the untreated cells $(\mathrm{P}<0.01)$. Correlation analysis between the positive expression rate of $\mathrm{Bcl}-\mathrm{xL}$ protein and the apoptosis rate in untreated T24 cells, T24 cells treated with $\beta$-elemene at different concentrations $(0.008,0.014$ and $0.02 \mathrm{mg} / \mathrm{ml})$ and T2 4 cells treated with the same concentration of $\beta$-elemene for different durations $(6,12$ and $18 \mathrm{~h})$, showed that when the positive expression rate of $\mathrm{Bcl}-\mathrm{xL}$ protein was low, the apoptosis rate was inversely high. This finding indicated that $\beta$-elemene could inhibit the expression of $\mathrm{Bcl}-\mathrm{xL}$ protein and induce the apoptosis of T24 cells, resulting in a decrease of the occurrence of bladder cancer. The expression of survivin and Bcl-xL proteins were positively correlated in T24 cells that were incubated with $\beta$-elemene, which indicated that when the expression level of survivin protein was low, the expression of Bcl-xL was also low. It is likely that survivin and Bcl-xL function at different stages of apoptosis. Bcl-xL functions upstream of caspase- 3 to inhibit the release of cytochrome from the mitochondrion, whereas survivin mainly functions downstream of Bcl-xL to directly inhibit the function of caspase-3, and the two proteins cooperate to inhibit apoptosis, which indicates that survivin and $\mathrm{Bcl}-\mathrm{xL}$ act in synergy promoting the occurrence and development of bladder cancer. As a result, $\beta$-elemene inhibits the occurrence and development of bladder cancer by downregulating the expression of survivin and Bcl-xL.

Metastasis-associated gene 1 (Mta-1) is a recently discovered gene that is associated with tumor metastasis (10). Cui et al (21) and others have discovered that the gene location of Mta-1 lies in chromosome 14q32.3, by using fluorescent in situ hybridization. The Mta-1 protein contains 703 amino acid residues with a molecular weight of $79.4 \mathrm{kDa}$, which includes the phosphorylation sites of tyrosine kinase protein kinase $\mathrm{C}$ and casein kinase 2, as well as the phosphorylation site and binding site of the src homology 3 domains (SH3), indicating that Mta-1 protein is capable of binding to other proteins to maintain normal cell function and plays a role in signal transduction pathways. Moreover, the existence of a leucine zipper motif indicates that the Mta-1 protein is likely to act as a transcription factor and thereby play a role in regulating gene expression.

Geng et al (22) have demonstrated that Mta-1 may be considered not only as a biomarker of aggressive diseases but also as a potential therapeutic target. In addition, results of research in the human osteosarcoma MG63 cell line showed that MG63 cells with high metastasis potential expressed significantly higher MTA1 levels than MG63 cells with low metastasis potential.

In this experiment, after adding $\beta$-elemene at a range of concentrations $(0.008-0.02 \mathrm{mg} / \mathrm{ml})$ and over various lengths of time (6-18 h), the bladder cancer T24 cells showed apoptosis by TUNEL analysis. Expression levels of both Mta-1 mRNA and protein analyzed by in situ hybridization, immunocytochemistry and western blotting revealed that the levels of Mta-1 mRNA and protein decreased upon $\beta$-elemene treatment, and the degree of the decrease was closely related to the dosage and incubation time of $\beta$-elemene. We found that with the reduced expression of Mta-1, the number of apoptotic tumor cells increased correspondingly. Statistical analysis revealed that there was a negative correlation between them $(\mathrm{p}<0.01)$, which indicated that Mta-1 may play a role in regulating bladder cancer cell apoptosis, and that the apoptosis of T24 cells induced by $\beta$-elemene may be the result of downregulation of the expression of Mta-1.

Moreover, the decreased expression level of Mta-1 in T24 cells induced by $\beta$-elemene resulted in the decreased expression of survivin and Bcl-xL, which indicated a close correlation between them. The decreased level of the expression of Mta-1 and the expression level of survivin and Bcl-xL were in proportion. The expression of Mta-1 began to decrease as early as $6 \mathrm{~h}$ after $\beta$-elemene treatment, while the expression of survivin and Bcl-xL began to decrease notably after $12 \mathrm{~h}$. The Mta-1 decrease was positively related to the decrease of the expression level of Mta-1, but negatively related to the increase in the number of apoptotic cells.

In conclusion, we found that the antiapoptosis mechanism of $\beta$-elemene, a non-cell toxic antitumor drug that is capable of effectively inhibiting the proliferation of tumor cells and inducing their apoptosis, may be associated with the downregulation of Mta-1, survivin and Bcl-xL expression. As $\beta$-elemene is efficient and safe, with few side-effects and little drug-resistance, it may be widely used for tumor treatment.

\section{Acknowledgements}

This research was supported by a scientific research fund from Hunan Science and Technology Bureau (2008FJ3221).

\section{References}

1. Tan W, Lu JJ, Huang MQ, et al: Anti-cancer natural products isolated from Chinese medicinal herbs. Chin Med 6: 27, 2011.

2. Li u J, Zhang Y, Qu JL, et al: $\beta$-Elemene-induced autophagy protects human gastric cancer cells from undergoing apoptosis. BMC Cancer 11: 183, 2011.

3. Yu Z, Wang R, Xu L, Xie S, et al: $\beta$-Elemene piperazine derivatives induce apoptosis in human leukemia cells through downregulation of c-FLIP and generation of ROS. PLoS One 6: e15843, 2011.

4. Oliver L, Hue E, Rossignol J, et al: Distinct roles of Bcl-2 and $\mathrm{Bcl}-\mathrm{xL}$ in the apoptosis of human bone marrow mesenchymal stem cells during differentiation. PLoS One 6: e19820, 2011.

5. Edlich F, Banerjee S, Suzuki M, et al: Bcl-x(L) retrotranslocates Bax from the mitochondria into the cytosol. Cell 145: 104-116, 2011.

6. Vogler M, Hamali HA, Sun XM, et al: BCL2/BCL-XL inhibition induces apoptosis, disrupts cellular calcium homeostasis, and prevents platelet activation. Blood 117: 7145-7154, 2011.

7. Li XP, Cunningham C, Wang GD, et al: Elemene and cisplatin synergistically induce apoptosis in chemoresistant ovarian carcinoma cells. Proc Amer Assoc Cancer Res 46: 410-411, 2005.

8. Petrarca CR, Brunetto AT, Duval V, et al: Survivin as a predictive biomarker of complete pathologic response to neoadjuvant chemotherapy in patients with stage II and stage III breast cancer. Clin Breast Cancer 11: 129-134, 2011.

9. Li XP, Wang GD, Cunningham C, et al: Elemene modulates cisplatin sensitivity in human ovarian cancer cells. Proc Amer Assoc Cancer Res 3: 193, 2004.

10. Toh Y,Pencil SD and Nicolson GL: A novel candidate metastasisassociated gene, mta1, differentially expressed in highly metastatic mammary adenocarcinoma cell lines. cDNA cloning, expression, and protein analyses. J Biol Chem 269: 22958-22966, 1994.

11. Kawasaki G, Yanamoto S, Yoshitomi I, Yamada S and Mizuno A: Overexpression of metastasis-associated MTA1 in oral squamous cell carcinomas: correlation with metastasis and invasion. Int J Oral Maxillofac Surg 37: 1039-1046, 2008.

12. Ambrosini G, Adida C and Altieri DC: A novel anti-apoptosis gene survivin expressed in cancer and lymphoma. J Nat Med 3: 917-921, 1997. 
13. Suzuki A and Kawano H: Survivin initiates procaspase 3/P21 complex formation as a result of interaction with CDK4 to resist Fas-mediated cell death. J Oncogene 19: 1346-1353, 2000.

14. Muchmore SW, Chen J, Jakob C, et al: Crystal structure and mutagenic analysis of the inhibitor of apoptosis protein survivin J Mol Cell 6: 173-182, 2000.

15. Chen YB, Tu JJ, Kao J, et al: Survivin as a useful adjunct marker for the grading of papillary urothelial carcinoma. Arch Pathol Lab Med 32: 224-231, 2008.

16. Gonzalez MS, De Brasi CD, Bianchini M, et al: BAX/BCL-XL gene expression ratio inversely correlates with disease progression in chronic myeloid leukemia. Blood Cells Mol Dis 45: 192-196, 2010.

17. Yang SB, Chen X, Wu BY, et al: Immunoglobulin kappa and immunoglobulin lambda are required for expression of the antiapoptotic molecule Bcl-xL in human colorectal cancer tissue. Scand J Gastroenterol 44: 1443-1451, 2009.

18. Li J, Cheng Y, Qu W, et al: Fisetin, a dietary flavonoid, induces cell cycle arrest and apoptosis through activation of p53 and inhibition of NF-kappa B pathways in bladder cancer cells. Basic Clin Pharmacol Toxicol 108: 84-93, 2011.
19. Guo S, Sun F, Guo Z, et al: Tyrosine kinase ETK/BMX is up-regulated in bladder cancer and predicts poor prognosis in patients with cystectomy. PLoS One 6: e17778, 2011.

20. Bolenz C, Weiss C, Wenzel MJ, et al: In vivo evaluation of intravesical paclitaxel and combined Bcl-xL antisense oligodeoxynucleotide treatment for orthotopic urothelial carcinoma. J Cancer Res Clin Oncol 135: 679-686, 2009.

21. Cui Q, Takiguchi S, Matsusue K, et al: Assignment of the human metastasis-associated gene 1 (MTA1) to human chromosome band $14 \mathrm{q} 32.3$ by fluorescence in situ hybridization. Cytogenet Cell Genet 93: 139-140, 2001.

22. Geng L, Deepak PA, Aija L, et al: Identification of metastasis associated antigen 1 (MTA1) by serological screening of prostate cancer cDNA libraries. Open Biochem J 2: 100-107, 2008. 